\title{
ANALISIS PENGENDALIAN PRODUK CACAT PADA KAYU LAPIS MENGGUNAKAN SQL (STATISTICAL QUALITY CONTROL) PADA PABRIK PT. WIJAYA TRI UTAMA PLYWOOD INDUSTRY
}

\author{
Kurnadi $^{1}$, Muhammad Marsudi ${ }^{1}$, Yassyir Maulana ${ }^{1}$ \\ Program Studi Teknik Industri, Fakultas Teknik \\ Universitas Islam Kalimantan Muhammad Arsyad Al Banjari Banjarmasin \\ Jl. Adhyaksa No 2 Kayu Tangi Banjarmasin 70123 Indonesia \\ e-mail : Kurnadistar97@gmail.com
}

\begin{abstract}
Abstrak- Penelitian ini didasarkan pada banyaknya produk cacat yang diproduksi oleh perusahaan. Tujuan dari penelitian ini adalah mengetahui kualitas produk kayu lapis serta mengidentifikasi pengendalian produk cacat pada PT. Wijaya Tri Utama Plywood Industry. Penelitian didesain sebagai penelitian Studi kasus yang bertempat di PT. Wijaya Tri Utama Plywood Industry di Banjarmasin pengambilan data dilakukan dengan dngan teknik observasi, wawancara, studi dokumentasi, dan studi pustaka. Teknik analisis mengacu pada ukuran metode analisis pada Statistical Quality Control, metode analisis mengunakan diagram pareto, analisis menggunakan $P$ Chart, dan diagram sebab akibat. Hasil Penelitian menunjukan bahwa pada pabrik PT. Wijaya Tri Utama Plywood Industry masih terdapat banyak produk cacat dengan jenis persentase berturut-turut Jenis cacat $O$ ver Laps $14,62 \%$, jenis cacat Face pecah $11,62 \%$, jenis cacat Face Kasar 10,46\%, jenis cacat Delaminasi 9,9\%, jenis cacat size kurang $9,60 \%$. Adanya nilai proporsional yang melampaui nilai UCL dan LCL yang menunjukan kualitas produksi dari PT. WTUPI masih kurang. Fishbone menunjukan penyebab adanya cacat produk terbesar adalah berada pada faktor manusia. Belum ada kendali untuk memperbaiki proses produksi kayu lapis dari PT. WTUPI. Produksi kayu lapis perlu perbaikan pengendalian kualitas dan mengevaluasi untuk mendapatkan hasil yang lebih baik lagi .
\end{abstract}

Kata Kunci : Pengendalian Produk Cacat, Statistical Quality Control,

\section{PENDAHULUAN}

I ndustri kayu di Indonesia mengalami perkembangan positif dari tahun ke tahun terutama kayu lapis. PT. Wijaya Tri Utama Plywood Industry adalah salah satu pabrik kayu lapis yang berada di Banjarmasin Kalimantan Selatan. Kualitas produk kayu lapis merupakan faktor dengan nilai urgensi terpenting dalam dunia industri.

Kualitas suatu produk diukur dengan banyak penilaian yang telah ada. Produk industry kayu memiliki nilai kualitas kontrol untuk meminimalisir adanya produk cacat [7]. Produk cacat pada kayu lapis dapat memengaruhi penjualan dan standar kualitas kontrol dari produk tersebut. sebuah perusahaan wajib memiliki standar kualitas kontrol tersendiri.

Jenis kecacatan produk juga berbeda-beda tergantung ada tingkat keparahan, jenis kerusakan dan letak kerusakan. Dalam (Andiwibowo, Susetyo, dan Wisnubroto, 2018) bahwa Jenis kecacatan produk plywood ada beberapa macam yaitu :

1. Over Laps

Keadaan dimana peletakan kayu lapis menghimpit hingga tergores benda lain sehingga tidak memenuhi standar mutu.

2. Face Pecah

Permukaan pecah yang disebabkan kurang merata dalam pengeringan venir dan penanganannya kurang hati-hati.

3. Face Kasar

Di mana keadaan permukaan kayu kasar dan tidak memenuhi persyaratan mutu.

4. Delaminasi

Pelaburan perekat tidak merata, perekat pada bagian tepi agak kering, masa tunggu tertutup terlalu lama, dan mengelupaskan bagian tepi venir sehingga tidak memenuhi standar

5. Size Kurang

Keadaan di mana ukuran venir lebih pendek daripada ukuran kayu lapis sehingga tidak sesuai dalam persyaratan produksi .

6. Noda

Bagian pada permukaan yang berubah warna dari warna asli kayu karena pengaruh bahan lain. Macam noda disebut berdasarkan macam bahan penyebabnya: noda dempul, noda oli, noda perekat, noda pita perekat, noda minyak, noda kapur berwarna. Dalam ISO tidak disebut noda tetapi ada penembusan perekat (dari garis rekat).

7. Terbentur

Garis pertemuan sisi tebal antara dua lembar venir pada bidang sama sehingga meimbulkan goresn pada kayu

8. Press Mark

Adalah cacat dalam pengempaan yang disebabkan kayu lapis yang dimasukan kedalam hot press terdapat lapisan.

9. Berlubang

Di mana venir berongga akibat dimakan cacing laut dan parasit sehingga venir menyebabkan tidak tidak rata dan tidak menuhi standar mutu. 
10. Core Ujung Kurang Lapisan tengah kurang pada arah memanjang, inditifikasi nya tengah venir kosong pada bagian ujung tampak kosong pada arah melebar.

Metode Statistical Quality Control (SQC) merupakan salah satu metode statistic yang digunakan untuk mengetahui standar kualitas kontrol suatu produk. Statistical Quality Control (SQC) memungkinkan kita bisa menghitung kualitas kontrol dari produk cacat atau pun non cacat yang telah diproduksi (Freeman, Cook, and ... 2021). Hal ini menjadi tolak ukur mutu dari produk yang dihasilkan suatu perusahaan.

Penerapan Statistical Quality Control (SQC) pada Pabrik PT. Wijaya Tri Utama Plywood Industry ini akan mengukur kualitas produk terutama produk cacat yang dihasilkan.

Tujuan penelitian ini dilakukan adalah untuk mengidentifikasi kualitas produk yang dihasilkan oleh PT. Wijaya Tri Utama Plywood Industry serta mengetahui penerapan pengendalian produk cacat dengan menggunakan Statistical Proces Control.

\section{METODE PENELITIAN}

Penelitian ini di deain sebagai penelitan studi kasus yang dilakukan di pabrik PT. Wijaya Tri Utama Plywood Industry yang terletak di Banjarmasin. Pengambilan data dilakukan pada Januari sampai Desember 2019.

\section{Sumber data}

1. Data Primer

Data primer berupa data yang diambil dari lapangan yang berdasarkan pada observasi, waancara dan dokumenntasi yang bersumber dari lingkungan, karyawan dan narasumber.

2. Data Sekunder

Data sekunder dalam penelitian ini menggunakan segala dokumen, catatan dan literature yang relevan dengan penelitian ini.

\section{Metode Pengambilan Data}

Data diambil dengan menggunakan metode observasi, wawancara, studi dokumentasi serta studi pustaka.

\section{Teknik analisis data}

Teknik analisa data dalam penelitian ini mengacu pada ukuran metode analisis pada Statistical Quality Control(Montgomery 2020) dalam menentukan batas produk cacat, metode analisis mengunakan diagram pareto (Knoth and Schmid 2018), analisis menggunakan P-Chart, dan diagram sebab akibat.

\section{HASIL DAN PEMBAHASAN}

\section{a. Check sheet}

Check Sheet dirancang guna menemukan pola data serta mengumpulkan data, agar mampu mendapat pola data. Dalam hal ini, PT. Wijaya Tri Utama Plywood Industry mampu memproduksi 1800 lembar kayu lapis, yang terdiri dari shift kerja. Karena produktiivitas dua shift adalah sama, maka satu shift mampu menghasilkan setengah dari total produksi dengan jumlah 900 lembar. Jumlah tersebut dibagi 12 bulan penelitian kemudian didapatkan sampel dengan jumlah 150 .

Data yang dikumpulkan hasil Cheeck Sheet tertera dalam tabel sebagai berikut:

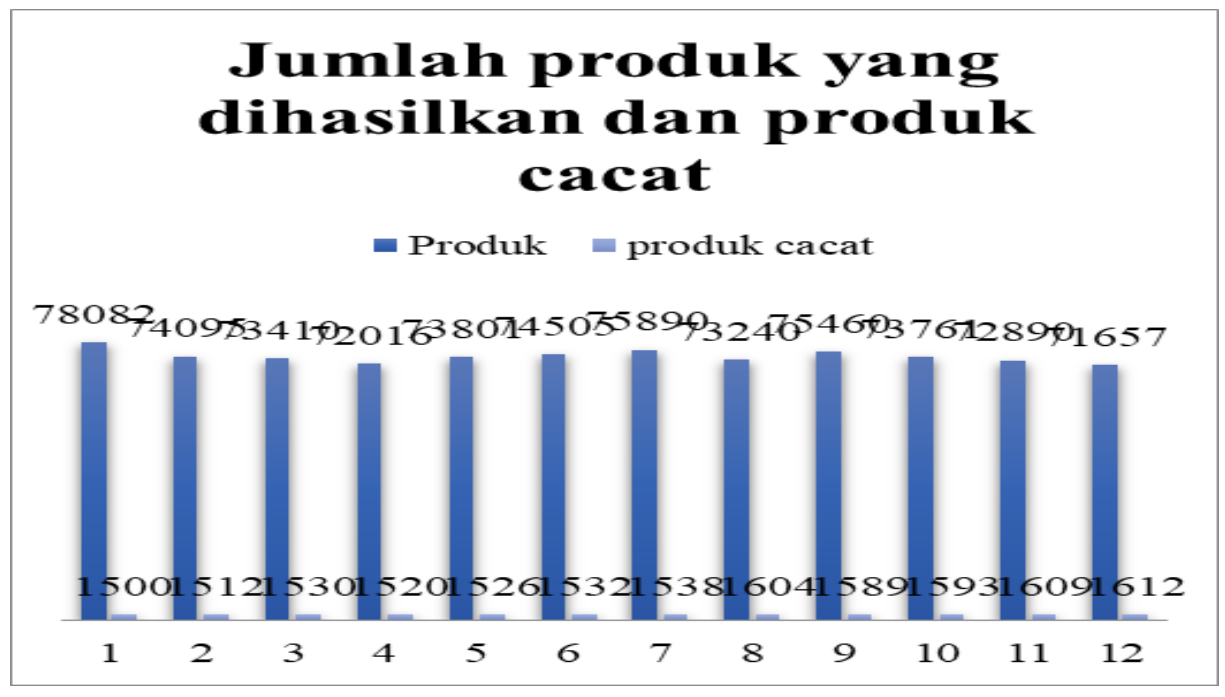

Gambar 1. Jumlah Produk Cacat dan Jumlah Produksi 2019 Dalam (m³)

Menurut Awaliyah, M. Novitasari Mara, Shantika Martha 2016, data perlu diuji untuk melihat jenis distribusi data tersebut. apakah data tersebut terdistribusi dengan normal atau pun tidak, agar dapat melanjutkan ke perhitungan selanjutnya.
Setiap produk cacat memiliki kategori berbeda-beda tergantung jenis dan tingkat kecacatan, berikut adalah tabel jenis kecacatan produk kayu lapis dari PT. Wijaya Tri Utama Plywood Industry. 
Tabel 1. Jenis Cacat Produk dan Jumlah

\begin{tabular}{|c|c|c|c|c|c|c|c|c|c|c|c|c|}
\hline & & & & & Jenis produk & cacat & & & & & & \\
\hline & & Over & Face & Face & & Size & & Press & & & & \\
\hline No Pengamatan & Sampel & Laps & Pecah & Kasar & Delaminasi & Kurang & Terbentur & Mark & Berlubang & Noda & CoreUjung & Jumlah Cacat \\
\hline 1 Januari & 150 & 178 & 180 & 162 & 140 & 150 & 140 & 145 & 160 & 110 & 135 & 1500 \\
\hline Febuari & 150 & 196 & 150 & 168 & 156 & 152 & 143 & 147 & 135 & 143 & 122 & 1512 \\
\hline maret & 150 & 219 & 164 & 155 & 160 & 145 & 139 & 134 & 138 & 163 & 113 & 1530 \\
\hline April & 150 & 221 & 156 & & 168 & 143 & 132 & 147 & 124 & 143 & 128 & 1520 \\
\hline Mei & 150 & 231 & 159 & 162 & 160 & 144 & 141 & 140 & 126 & 131 & 132 & 1526 \\
\hline Juni & 150 & 249 & 178 & 157 & 162 & 149 & 138 & 121 & 124 & 132 & 122 & 1532 \\
\hline Juli & 150 & 236 & 164 & 133 & 156 & 125 & 109 & 162 & 162 & 187 & 104 & 1538 \\
\hline 8 Agustus & 150 & 229 & 184 & 169 & 151 & 150 & 137 & 154 & 149 & 158 & 123 & 1604 \\
\hline 9 September & 150 & 250 & 194 & 174 & 153 & 148 & 122 & 145 & 138 & 120 & 145 & 1589 \\
\hline 10 Oktober & 150 & 234 & 205 & 169 & 138 & 172 & 128 & 131 & 145 & 137 & 134 & 1593 \\
\hline 11 November & 150 & 240 & 213 & 170 & 140 & 159 & 137 & 122 & 138 & 145 & 145 & 1609 \\
\hline 12 Desember & 150 & 247 & 223 & 177 & 159 & 150 & 122 & 112 & 137 & 138 & 147 & 1612 \\
\hline Jumlah & 1800 & 2730 & 2170 & 1954 & 1843 & 1787 & 1588 & 1660 & 1676 & 1707 & 1550 & 18665 \\
\hline
\end{tabular}

Tabel di atas menunjukan bahwa banyak jenis kecacatan yang terjadi, begitu pula dengan jumlahnya. Data di atas menunjukan hasil bahwa OverLaps sebesar 2730 Pcs = 14,62\%, Face pecah sebesar 2170 Pcs $=11,62 \%$, Face Kasar sebesar 1954 Pcs $=10,46 \%$, Delaminasi sebesar 1843 Pcs $=$ $9,9 \%$, size kurang sebesar 1787 Pcs $=9,60 \%$, Noda sebesar 1707 Pcs $=9,14 \%$, Berlubang sebesar 1676 Pcs $=9,00 \%$, Press Mark sebesar 1660 Psc $=8,90 \%$, Terbentur sebesar 1588 Pcs $=8,50 \%$, Core Ujung kurang sebesar $1550 \mathrm{pcs}=8,30 \%$
Data di atas menunjukan bahwa produk cacat yang dihasilkan dari proses produksi masih besar. Hal ini dapat dilhat dari masih tingginya persentase produk cacat.

\section{b. Diagram Pareto}

Mengklasifikasi tingkat kecacatan dari yang kecil hingga yang besar dan juga menunjukan frekuensi kuantitasnya. Nilai persentase kumulatif pada diagram Pareto, berguna untuk menentukan kategori jenis kecacatan produk hasil produksi yang paling sering dan parah pada permasalahan.

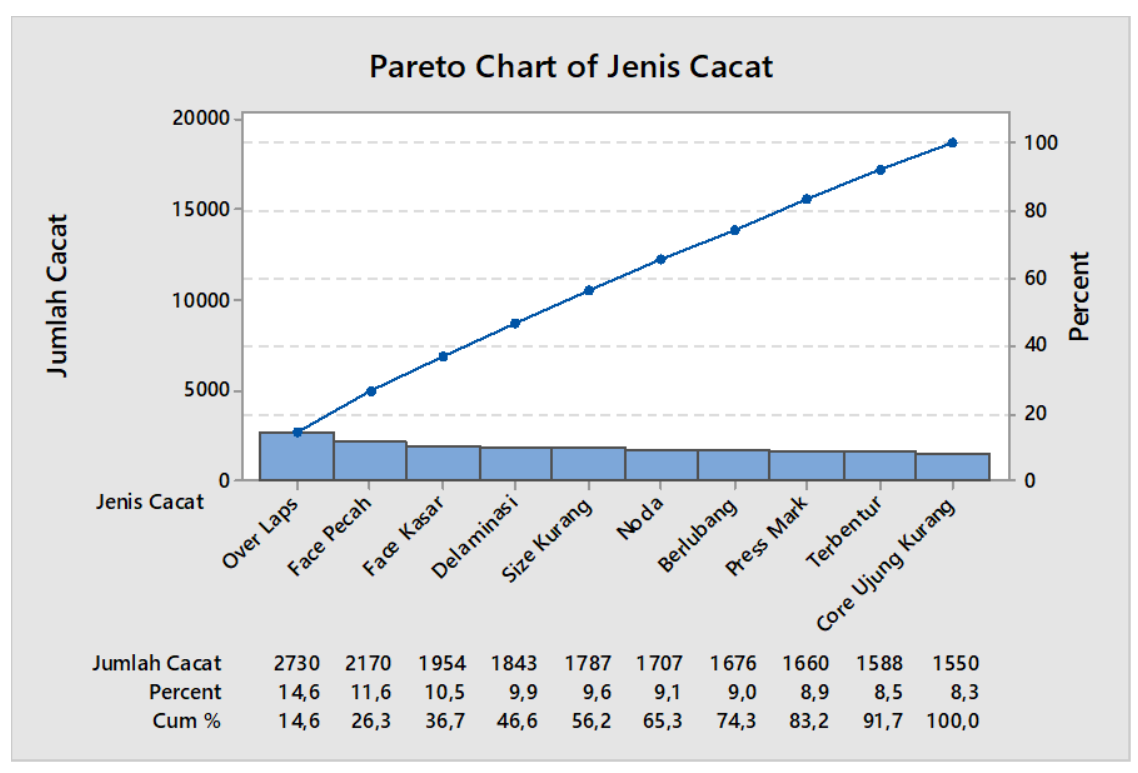

Gambar 2. Diagram Pareto dari Jenis Cacat 
Berdasarkan nilai persentase kumulatifnya, dapat dilihat Overlaps, face pecah dan face kasar merupakan tiga besar jenis cacat terbesar dengan nilai $36,7 \%$ dari seluruh total cacat. Nilai persentase kecacatan 3 terbesar saja sudah mencapai $36,7 \%$, artinya sudah melebihi dari sepertiga dari jumlah kecacatan yang hanya didominasi oleh tiga jenis cacat terbesar.

Nilai persentase sepuluh terbesar yaitu kecacatan Lain-lain meliputi dalam nilai OverLaps $14,6 \%$, Face pecah 11,6\%, FaceBack/kasar 10,5\% .Delaminasi 9,9\%, Size Kurang 9,6\%, Noda lem 9,1 Berlubang 9,0\%, Press Mark 8,9\%, Terbentur $8,5 \%$ dan cacat Core ujung kurang $8,3 \%$.
Dengan diagram ini kita dapat efektif memusatkan perhatian pada sebab yang mempunyai dampak yang paling besar pada proses produksi.

\section{c. Diagram Kendali (Control Chart)}

Diagram memiliki Gambaran statistik dari nilai garis pusat (Central Line), batas kendali atas (Upper Control Limit) dan batas kendali bawah (Lower Control Limit) untuk menemukan halangan dan kejadian dari variasi yang terkendali dalam pengendalian proses produksi yang dilakukan, agar bisa memecahkan masalah dan menghasilkan perbaikan pada kualitas produk

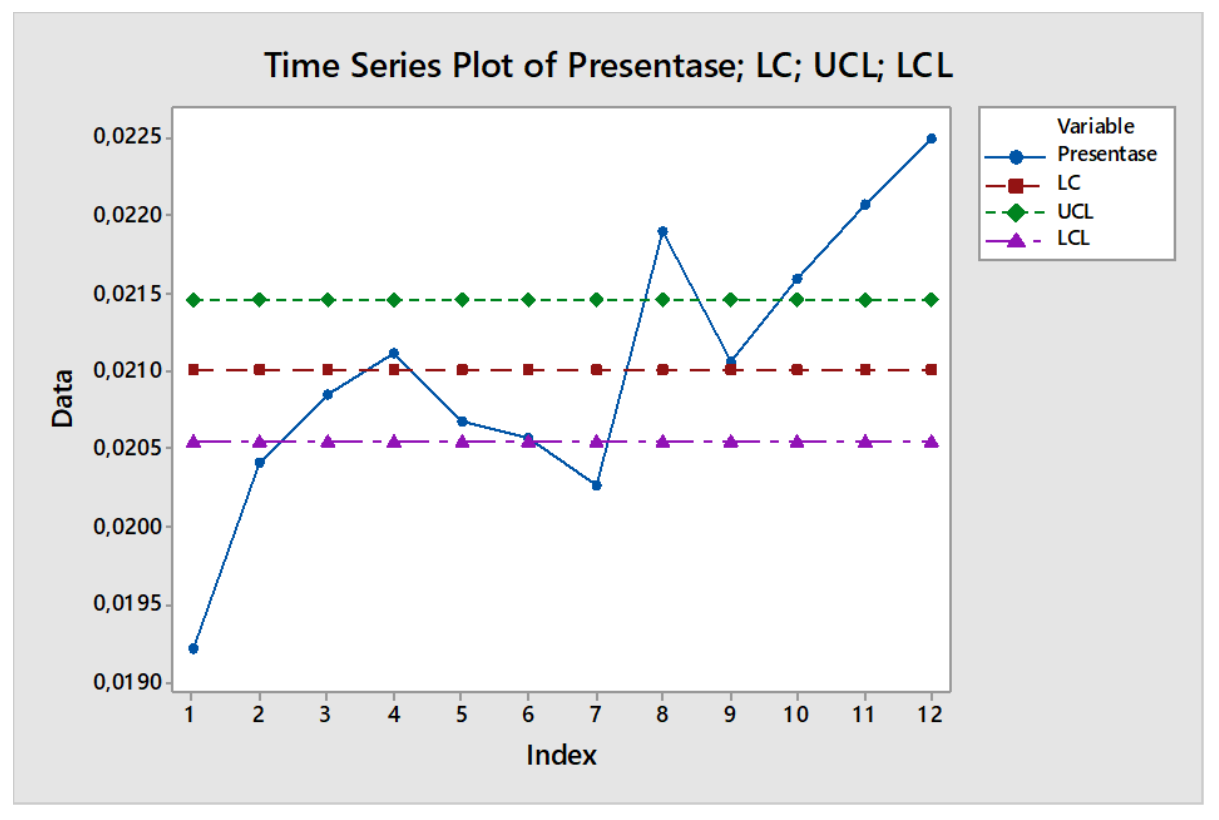

Gambar 3. Diagram Kendali/Kontrol dari Jenis Cacat

Berdasarkan diagram di atas nilai proporsi perusahan telah melewati UCL UCL dan LCL menggambarkan bahwa perusahaan tidak terkendali, perlu adanya perbaikan proses produksi sehingga kualias produksi dapat terkendali . produk cacat bulan Januari-desember 2019 dapat dilihat nilai $\mathrm{UCL}=0,021456327$, nilai $\mathrm{p}=$ 0,0210000596 dan niai $L C L=0,020543793$.

\section{d. Diagram Sebab Akibat (fishbone)}

Fishbone memperlihatkan hubungan antara permasalahan yang dihadapi dengan kemungkinan penyebabnya dan faktor yang mempengaruhinya, yang diperoleh dari hasil wawancara.

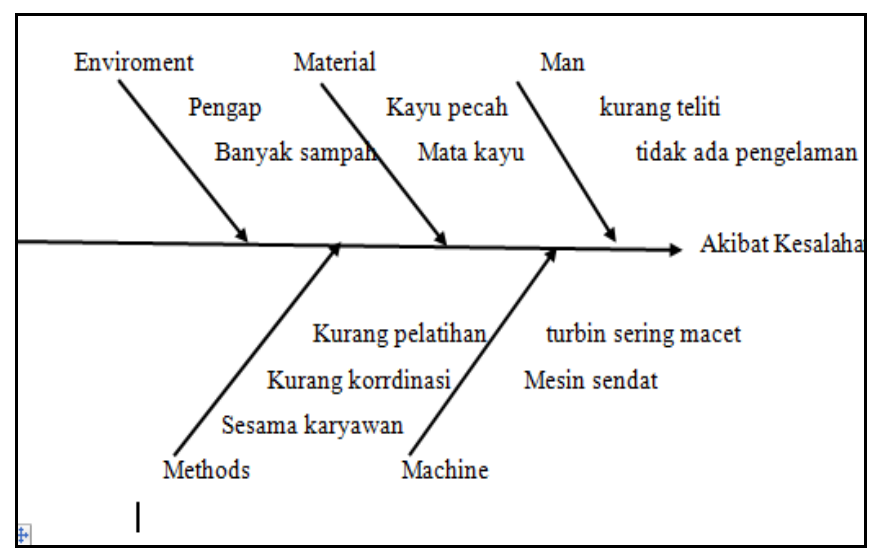

Gambar 4. Diagram Sebab Akibar (Fishbone) 
Penyebab adalah faktor manusia (human error), bahan baku, mesin, metode pengerjaan, dan lingkungan. Faktor sanding mati, mesin turbin macet, kadar air tinggi, lubang ulat, hati kayu, mata kayu, oli mesin menetes, tempat kerja pengap, banyak sampah, belum menguasai pekerjaan, dan kurang konsentrasi. Sebagai alat bantu untuk mencari penyebab terjadinya kecacatan, digunakan diagram Sebab Akibat.

\section{KESIMPULAN DAN SARAN}

\section{a. Kesimpulan}

Berdasarkan data hasil produksi kayu lapis PT WTUPI dapat diambil kesimpulan sebagai berikut:

1. Produksi kayu lapis pada Januari 2019 sampai desember 2019 terdapat beberapa beberapa titik yang keluar dalam batas kendali yaitu bulan Agustus dengan nilai $\mathrm{p}=0,021900601$, bulan oktober dengan nilai $\mathrm{p}=0,021596779$, bulan november dengan nilail $\mathrm{p}=0,022074359$ dan bulan desember dengan nilai $\mathrm{p}=$ 0,022496058 artinya produksi kayu lapis keluar dari batas kendali dengan nilai $\mathrm{ULC}=0,021456327$ dan nilai $\mathrm{LCL}=0,020543793$. Hal ini menunjukan kualitas produksi dari PT. WTUPI masih kurang. Fishbone menunjukan penyebab cacat produk terbesar adalah faktor manusia.

2. Hasil analisis Stastical Quality Control terdapat data dengan analisis peta kendali menunjukan bahwa pengendalian di PT WTUPI diluar batas kendali. Berdasarkan analisis menggunakan SQC tindakan yang sebaiknya dilakukan untuk mencegah kerusakan yaitu membuat Standar Operasional Procedure (SOP). penyebab Tersier, meliputi kurang koordinasi antar karyawan, kurang pelatihan mengenai pekerjaan, mesin

\section{b. Saran}

Memperbaiki sistem kerja pada bagian produksi baik segi karyawan, bahan baku dan mesin.

1. Mengontrol produk yang akan diproduksi sesuai dengan tenaga kerja dan mesin.

2. Melakukan usaha meningkatkan kinerja produksi pada pengupasan agar tidak ada lagi cacat dalam memproduksi kayu lapis, dan melakukan perencanaan serta mendukung pengawasan dalam proses kinerja karyawan.

\section{DAFTAR PUSTAKA}

[1] Awaliyah, M. Novitasari Mara, Shantika Martha. 2016. "Analisis Produksi Kayu Lapis Menggunakan Statistical Quality Control." Volume 05, No. 1 (2016), Hal 1-8.

[2] Muhammadd Nur Ilham,2008,Makassar t.t.) Analisis Pengendalian Kualitas Produk Dengan Menggunakan Statistical Processing Control (Spc) Pada PT. Bosowa Media Grafika (Tribun Timur).

[3] Burr, IW. 2018. Statistical Quality Control Methods. taylorfrancis.com.

[4] Freeman, KP, JR Cook, and ... 2021. "Introduction to Statistical Quality Control.” Journal of the American ... (Query date: 2021-0605 02:57:13).

[5] Knoth, S., and W. Schmid. 2018. Frontiers in Statistical Quality Control 12. Springer.

[6] Andiwibowo, RR, J. Susetyo, and P. Wisnubroto. 2018 "Pengendalian Kualitas Produk Kayu Lapis Menggunakan Metode Six Sigma \& Kaizen Serta Statistical Quality Control Sebagai Usaha Mengurangi Produk ....” Jurnal Rekavasi (Query date: 202106-05 03:07:06).

[7] Febryany, FG, Z. Ilmi, and ... 2019. "Pengendalian Kualitas Produk Kayu Lapis.” Jurnal Ilmu Manajemen ... (Query date: 2021-06-05 03:07:06). 